\title{
PENGEMBANGAN SOAL HIGHER ORDER THINKING SKILLS (HOTS) PADA MATERI SISTEM PERSAMAAN LINEAR TIGA VARIABEL (SPLTV) KELAS X SMA
}

\author{
Riski Ningsih', Annajmi² \\ Universitas Pasir Pengaraian \\ 2Universitas Pasir Pengaraian \\ Kikiningsih37@gmail.com
}

\begin{abstract}
This study discusses the development of the Higher Order Thinking Skill (HOTS) test instrument, the material for the three-variable linear equation system for class X SMA. This study aims to: 1) determine the steps in developing the HOTS test instrument, 2) Knowing the validity value of the HOTS test instrument. This study uses a type of research and development (Research and Development). The development model used is the Formative Research Tessmer type development model, which consists of 2 main stages: the preliminary stage and the formative evaluation stage. In stage 1 consists of preliminary and self-evaluation. In stage 2 , the formative evaluation includes prototyping. The data collection technique used was a test. The instruments used in this study were test instruments and validation sheets. Validity is known from the results of the validator's assessment on the validation sheet, which states that the test instrument has been well developed based on content (according to curriculum and material), construct (according to HOTS characteristics/indicators), language (following applicable language rules), time allocation and instructions question. Based on the prototype stage results, a predetermined quality criterion test instrument was produced, namely valid and overall suitable for use as a HOTS question.
\end{abstract}

Keywords: HOTS, Assessment, three-variable system of linear equations

ABSTRAK Penelitian ini membahas tentang pengembangan instrumen tes Higher Order Thinking Skill (HOTS) materi sistem persamaan linear tiga variabel kelas X SMA. Penelitian ini bertujuan untuk: 1) mengetahui langkah-langkah pengembangan instrumen tes HOTS, 2) Mengetahui nilai validitas dari instrumen tes HOTS. Penelitian ini menggunakan jenis penelitian pengembangan (Research and Development). Model pengembangan yang digunakan adalah model pengembangan tipe Formative Research Tessmer yang terdiri dari 2 tahapan utama yaitu tahapan preliminary dan tahapan formatif evaluation. Pada tahap I terdiri dari preliminary dan self-evaluation, pada tahap II formative evaluation meliputi prototyping. Teknik pengumpulan data yang digunakan yaitu tes. Instrumen yang digunakan dalam penelitian ini adalah instrumen tes dan lembar validasi. Kevalidan diketahui dari hasil penilaian validator pada lembar validasi yang menyatakan instrumen tes dikembangkan telah baik berdasarkan content (sesuai dengan kurikulum dan materi), construct (sesuai dengan karakteristik/indikator HOTS), bahasa (sesuai dengan kaidah bahasa yang berlaku), alokasi waktu dan petunjuk soal. Berdasarkan hasil yang diperoleh pada tahap prototype dihasilkan instrumen tes kriteria kualitas yang telah ditetapkan yaitu valid dan secara keseluruhan sudah layak digunakan sebagai soal HOTS.

Kata-kata Kunci : HOTS, Penilaian, SPLTV 


\section{PENDAHULUAN}

Asesmen merupakan suatu proses dimana informasi diperoleh berkaitan dengan tujuan pembelajaran. Penilaian merupakan proses pengumpulan informasi tentang pencapaian belajar peserta didik, untuk digunakan sebagai dasar dalam membuat keputusan (Mardapi, 2012). Asesmen juga merupakan proses penyimpulan berbagai fakta-fakta dan membuat pertimbangan dasar yang profesional untuk mengambil kebijakan pada sekumpulan informasi, yang berupa informasi tentang peserta didik (llyas, 2012). Asesmen adalah istilah yang luas yang mencakup tes (pengujian). Tes adalah bentuk khusus dari asesmen. Tujuan utama dari penilaian adalah untuk meningkatkan kualitas pendidikan, karena penilaian dapat mengomunikasikan apa yang diharapkan dan apa yang telah dicapai dalam kegiatan pembelajaran (Mardhiyana \& Jailani, 2018). Dalam standar penilaian pada kurikulum 2013 dijelaskan bahwa penilaian siswa dalam proses pembelajaran sangat erat kaitannya dengan keterampilan berpikir. HOTS atau Higher Order Thinking Skill merupakan kemampuan berpikir tingkat tinggi sebagai gabungan dari berpikir kritis, berpikir kreatif dan berpikir pengetahuan dasar. Minarni (Annajmi A. , 2016) menjelaskan bahwa untuk menguasai matematika tingkat lanjut maka diperlukan kemampuan berpikir matematik tingkat tinggi (high order thinking skills) yang meliputi kemampuan pemahaman, penalaran, koneksi dan representasi serta kemampuan pemecahan masalah. Kemampuan berpikir tingkat tinggi adalah proses berpikir yang mengharuskan siswa untuk memanipulasi informasi dan ide-ide dalam cara tertentu yang memberi mereka pengertian dan implikasi baru (Gunawan, 2012). Peningkatan keterampilan berfikir tingkat tinggi telah menjadi salah satu prioritas dalam pembelajaran matematika sekolah. Peraturan Menteri Pendidikan Nasional nomor 22 Tahun 2016 menyatakan mata pelajaran Matematika diberikan kepada semua peserta didikuntuk membekali mereka dengan kemampuan berpikir logis, analitis, sistematis, kritis, dan kreatif, serta kemampuan bekerjasama (Mendikbud, 2016). Salah satu tujuan pembelajaran matematika untuk Sekolah Menengah Atas menurut Badan Standar Nasional Pendidikan (BSNP, 2006) ialah siswa memiliki kemampuan memecahkan masalah yang meliputi kemampuan memahami masalah, merancang model matematika, menyelesaikan model dan menafsirkan solusi yang diperoleh. Berdasarkan tujuan tersebut sudah sepantasnya kemampuankemampuan yang telah disebutkan seharusnya dimiliki oleh siswa. Hal ini sesuai dengan tujuan mata pelajaran matematika yang termuat pada Permendikbud Nomor 58 Tahun 2014 menyatakan bahwa melalui mata pelajaran matematika agar peserta didik agar peserta didik memiliki kemampuan memahami konsep matematika, memecahkan masalah, mengkomunikasikan gagasan dengan simbol, tabel, diagram, atau media lain untuk memperjelas keadaan atau masalah (Hafisani, Annajmi, \& Arcat., 2020). Selain itu, National Council of Teacher Mathematics (NCTM, 2000) mengemukakan bahwa terdapat lima keterampilan proses yang dimiliki peserta didik melalui mata pelajaran matematika yang tercakup dalam standar proses, yaitu pemecahan masalah, penalaran dan pembuktian, komunikasi, koneksi, dan representasi. Keterampilan- keterampilan tersebut termasuk pada berpikir matematika tingkat tinggi (high order mthematical thinking) (Budiman \& Jailani, 
2014). Proses pembelajaran matematika yang dilaksanakan di sekolah saat ini masih belum menunjukkan tercapainya tujuan pembelajaran matematika secara maksimal. Tujuan pembelajaran akan tercapai, apabila pembelajaran dilaksanakan dengan efektif. Pembelajaran efektif merupakan pembelajaran yang memfasilitasi pelajar untuk belajar dengan mudah, menyenangkan dan dapat mencapai tujuan pembelajaran (Annajmi A. , 2018).

Berdasarkan hasil survei TIMSS dan PISA menunjukkan bahwa kemampuan siswa Indonesia dalam pembelajaran matematika masih sangat jauh dari rata-rata internasional. Hasil survei TIMSS tahun 2011 dan 2015 menunjukan skor pencapaian hasil belajar matematika peserta didik berturut-turut 386 dan 397 dengan skor ratarata 500. Dengan kriteria TIMSS membagi pencapaian peserta survei ke dalam empat tingkat: rendah (low 400), sedang (intermediate 475), tinggi (high 550) dan lanjut (advanced 625) dari data yang diperoleh posisi Indonesia berada pada tingkat rendah (Novaliyosi dan Hadi, 2019).

Salah satu faktor penyebabnya antara lain karena peserta didik di Indonesia kurang terlatih dalam menyelesaikan soal-soal kontekstual, menuntut penalaran, argumentasi dan kreativitas dalam meyelesaikannya, dimana soal-soal tersebut merupakan karakteristik soal-soal TIMSS (Budiman \& Jailani, 2014). Hal ini sesuai dengan Kemdikbud yang menyatakan bahwa rendahnya prestasi siswa Indonesia tersebut disebabkan oleh banyaknya materi uji di TIMSS yang tidak terdapat dalam kurikulum Indonesia. Peserta didik tidak akan mempunyai kemampuan berpikir tingkat tinggi jika tidak diberikan kesempatan untuk mengembangkan dan tidak diarahkan untuk itu (Arifin, 2009). Permasalahan yang terjadi di sekolah dimana guru matematika pada umumnya hanya menggunakan soal yang diambil dari buku paket (Nurmadinah, 2017). Soal yang diambil tersebut lebih kebanyakan hanya soal yang termasuk kemampuan berpikir tingkat rendah, dan jarang memberikan soal dengan aspek penalaran, dimana penalaran termasuk dalam kategori kemampuan berpikir tingkat tinggi dan kemampuan guru dalam membuat tes HOTS masih kurang serta belum tersediannya tes yang didesain untuk melatih HOTS. Sementara itu berdasarkan observasi yang telah dilakukan sebelumnya, permasalahan yang sama juga terjadi di sekolah SMAN 2 Rambah Hilir, bahwa masih kurang tersediannya soalsoal yang didesain khusus untuk melatih HOTS, guru lebih banyak menggunakan soalsoal yang ada dibuku paket. Salah satu solusi dari permasalahan ini yaitu perlunya dikembangkan instrumen tes untuk mengukur kemampuan berpikir tingkat tinggi (Higher Order Thinking Skill).. Adapun materi instrumen soal HOTS yaitu materi sistem persamaan linear tiga variabel, yang mana materi ini berdasarkan hasil wawancara materi tersebut merupakan materi matematika yang membutuhkan analisis kemudian menuntut pemahaman konsep yang tinggi sehingga perlu untuk dikembangkan menjadi sebuah soal HOTS. Maka dari itu, tes materi sistem persamaan linear tiga variabel sesuai untuk pengembangan instrumen berbasis HOTS yang valid sehingga perlu dikembangkan untuk sumber belajar alternatif siswa dan dapat pula digunakan oleh guru sebagai sumber alternatif dalam membuat instrumen tes agar lebih bervariasi dan sesuai dengan level HOTS. Karakteristik soal HOTS tersebut diantaranya adalah non algoritmik, bersifat kompleks, multiple solutions 
(banyak solusi), melibatkan variasi pengambilan keputusan dan interpretasi dan bersifat effortful (membutuhkan banyak usaha) (Resnick, 1987)

Berdasarkan latar belakang yang telah dijelaskan, maka tujuan penelitian ini adalah untuk mengembangkan instrument tes berbasis HOTS yang valid pada materi sistem persamaan linear tiga variabel untuk siswa SMA.

\section{METODE PENELITIAN}

Jenis penelitian penelitian ini adalah penelitian Pengembangan (Research and Development), yaitu metode penelitian yang digunakan untuk mengembangkan atau memvalidasi produk-produk yang digunakan dalam pendidikan dan pembelajaran (Arikunto, 2015). Adapun produk yang akan dikembangkan dalam penelitian ini ialah soal berbasis Higher Order Thinking Skills (HOTS) pada materi sistem persamaan linear tiga variabel (SPLTV) untuk siswa SMA/MA.

Model pengembangan yang digunakan adalah model pengembangan tipe formative research Tessmer (1993). Penelitian ini terdiri dari 2 tahapan utama yaitu tahapan preliminary (tahapan persiapan/ pertama) dan tahapan formative evaluation (Tahap II). Pada tahap I terdiri dari preliminary dan self evaluation, kemudian pada tahap II atau formative evalution langkah-langkah yang diambil mengikuti langkah-langkah yang dikemukakan oleh Tessmer yang meliputi prototyping (expert review).

Tahap persiapan (Preliminary) atau Tahap I Pada tahap persiapan atau preliminary dilakukan pengkajian terhadap beberapa sumber referensi yang berkaitan dengan penelitian ini.

Tahap Penilaian Sendiri (Self Evaluation) dilakukan penilaian oleh diri sendiri terhadap desain instrumen tes kemampuan berpikir tingkat tinggi yang dibuat oleh peneliti. Tahap ini dibagi menjadi 2 tahap yaitu analisis dan desain. Tahap analisis ini terdiri dari analisis kurikulum, analisis peserta didik dan analisis materi.

Tahap Formative Evaluation/ Prototyping (Validasi, Evaluasi, dan Revisi) produk yang telah dibuat atau didesain, selanjutnya dievaluasi. Hasil desain pada prototype pertama yang dikembangkan atas dasar self evaluation diberikan pada pakar (Expert Review) atau validator, dan hasilnya dijadikan bahan revisi. Validator pada penelitian ini terdiri dari dua orang, yaitu satu dosen pendidikan matematika dan satu guru bidang studi matematika.

Instrumen pengumpulan data lembar validasi, validasi dilakukan berdasarkan validasi materi, konstruksi danbahasa, dengan meminta pertimbangan dan penilaian dari validator. Penilaian tersebut diberikan pada instrumen lembar validasi instrumen tes kemampuan berpikir tingkat tinggi berarti sahih, artinya keabsahan instrumen itu tidak diragukan lagi (Hamzah, 2014). Berdasarkan nilai- nilai tersebut selanjutnya ditentukan nilai rerata total untuk semua aspek, selanjutnya nilai rerata total untuk semua soal diberikan kategori berdasarkan Sinaga (Annajmi \& Asra, Pengembangan Lembar Kegiatan Siswa (LKS) Berbasis Metode Penemuan Terbimbing untuk Meningkatkan Kemampuan Pemahaman Konsep Matematik Siswa Kelas VII SMP Islam Kepenuhan Kabupaten Rokan Hulu, 2017) untuk menentukan tingkat validasi instrument tes kemampuan berpikir tingkat tinggi siswa, disajikan pada Tabel 1. 
Tabel 1 Kategori Tingkat Kevalidan

\begin{tabular}{cc}
\hline Nilai & Tingkat Kevalidan \\
\hline$V_{a}=5$ & Sangat Valid \\
\hline $4 \leq V_{a}<5$ & Valid \\
\hline $3 \leq V_{a}<4$ & Cukup Valid \\
\hline $2 \leq V_{a}<3$ & Kurang Valid \\
\hline $0 \leq V_{a}<1$ & Tidak Valid \\
\hline
\end{tabular}

\section{HASIL DAN PEMBAHASAN}

Pengembangan instrumen tes kemampuan berpikir tingkat tinggi pada materi Sistem Persamaan Linear Tiga Variabel (SPLTV) dialkukan dengan sesuai dengan langkahlangkah pengembangan yaitu tahap preliminary, tahap self-evaluation, tahap prototyping. Adapun data hasil penelitian yang diperoleh setiap tahapan pengembangan, diuraikan sebagai berikut Tahap Preliminary,

Tahap ini dimulai dengan pengumpulan beberapa referensi yang berhubungan dengan penelitian ini, penelitian ini tentang pengembangan instrumen tes untuk mengukur kemampuan berpikir tingkat tinggi. Beberapa teori dan informasi sudah terkumpul, akan dilakukan kegiatan penentuan tempat dan subjek uji coba dengan cara menghubungi kepala sekolah dan guru mata pelajaran matematika di sekolah yang akan dijadikan lokasi penelitian serta mengadakan persiapan-persiapan lainnya, seperti mengatur jadwal penelitian dan prosedur kerjasama dengan guru kelas yang akan dijadikan sebagai tempat penelitian.

Tahap Self-evaluation,

Tahap ini adalah merancang instrumen tes kemampuan berpikir tingkat tinggi yang berdasarkan pada hasil tahap Preliminary. Instrumen tes ini dirancang terdiri dari kisikisi tes, soal tes, jawaban tes, dan pedoman penskoran. Tahapan ini terdiri dari dua kegiatan yaitu tahap analisis kurikulum dan tahan desain.

1). Analisis Kurikulum pada langkah ini dilakukan terhadap kurikulum matematika, literatur, dan tantangan serta tuntutan kurikulum 2013 kemudian akan ditinjau tujuan pembelajaran, sehingga diperoleh instrument tes yang dapat mengukur kemampuan higher order thinking skill. Bagian ini mengidentifikasi, merinci, dan melakukan analisis pada materi sistem persamaan linear tiga variabel (SPLTV) untuk siswa SMA/MA. Hasil analisis kebutuhan materi dari KI dan KD yaitu: KD 3.4. Menyusun sistem persamaan linear tiga variabel dari masalah kontekstual. Analisis ini merupakan langkah awal untuk perancanagan prototype agar sesuai dengan KD dan KI materi sistem persamaan linear tiga variabel.

2). Tahap Desain, Kegiatan yang dilakukan pada tahap desain ini, peneliti mendesain kisi-kisi soal pada instrumen tes, soal-soal instrumen tes kemampuan 
higher order thinking skills dan kunci jawaban instrumen tes. Desain produk ini sebagai prototype. Prototype fokus pada tiga karakteristik yaitu: pokok bahasan, konstruksi dan bahasa sesuai dengan lembar validasi.

Tahap Prototyping

Tahap ini adalah validasi perangkat oleh validator yang disertai dengan revisi. Hasil kegiatan tahap prototype ini adalah hasil validasi, validasi instrument dilakukan dengan memberikan lembar validasi instrument kisi-kisi tes, soal tes.Kunci jawaban dan pedoman penskoran soal kepada validator, yang terdiri dari atas satu dosen matematika (validator 1) dan satu guru matematika SMAN 2 Rambah Hilir (validator 2). Berdasarkan analisis dari 5 aspek penilaian validitas instrument tes di atas maka diperoleh penialaian hasil validasi keseluruhan adalah sebagai berikut.

Tabel 2. Hasil Validasi Instrumen Tes HOTS Keseluruhan Aspek

\begin{tabular}{clccc} 
& & Aspek Yang Dinilai & \multicolumn{2}{c}{$\begin{array}{c}\text { Jumlah Skor Dari } \\
\text { Nalidator }\end{array}$} \\
\cline { 3 - 5 } & & $\mathbf{1}$ & $\mathbf{2}$ \\
\hline 1 & Isi & 4.5 & 4 \\
\hline 2 & Kontruksi & 4 & 4 \\
\hline 3 & Bahasa Soal & 4.33 & 4 \\
\hline 4 & Alokasi Waktu & 4 & 4 \\
\hline 5 & Petunjuk Soal & 4 & 4 \\
\hline Rata- rata Keseluruhan Aspek & \multicolumn{3}{c}{4.08} \\
\hline Kategori & \multicolumn{3}{c}{ Valid } \\
\hline
\end{tabular}

Berdasarkan Tabel 2, terlihat skor rata- rata hasil validasi Instrumen tes HOTS adalah 4.08, dengan demikian dapat disimpulkan Instrumen tes HOTS valid.

\section{KESIMPULAN DAN SARAN}

Berdasarkan hasil dan pembahasan setiap tahapan pengembangan yang telah dilakukan, disimpulkan sebagai berikut. 1. Langkah-langkah pengembangan instrumen tes kemampuan berpikir tingkat tinggi melalui tahapan yaitu; (a) tahap preliminary, (b) tahap self evaluation (analisis kurikulum, materi, siswa), (c) Tahap prototyping (validasi) yang meliputi expert review. 2. Instrumen tes yang telah dikembangkan memenuhi kriteria kualitas yang telah ditetapkan yaitu valid dan instrumen tes secara keseluruhan sudah layak digunakan. Instrumen tes secara umum dinyatakan valid dengan interpretasi tinggi dengan melihat nilai yang dihasilkan adalah 4.08 . 


\section{DAFTAR PUSTAKA}

Annajmi, A. (2016). Peningkatan Kemampuan Pemahaman Konsep Matematik Siswa SMP Melalui Metode Penemuan Terbimbing Berbantuan Software Geogebra. MES: Journal of Mathematics Education and Science, 1-10.

Annajmi, A. (2018). Aktivitas Kerjasama (Collaboration) Mahasiswa dalam Pembelajaran Kooperatif Make a Match Melalui Implementasi Lesson Study. Jurnal Absis: Jurnal Pendidikan Matematika Dan Matematika, 43-54.

Annajmi, A., \& Asra, A. (2017). Pengembangan Lembar Kegiatan Siswa (LKS) Berbasis Metode Penemuan Terbimbing untuk Meningkatkan Kemampuan Pemahaman Konsep Matematik Siswa Kelas VII SMP Islam Kepenuhan Kabupaten Rokan Hulu. Jurnal Eksakta Pendidikan (JEP), 39-46.

Arifin. (2009). Evaluasi Pembelajaran. Bandung: Remaha Rosdakarya.

Arikunto, S. (2015). Dasar-Dasar Evaluasi Pendidikan. Jakarta: Bumi Aksara.

BSNP, B. S. (2006). Standar isi untuk satuan. Jakarta: Direktorat Jenderal Pendidikan Dasar dan Menengah.

Budiman, A., \& Jailani. (2014). Pengembangan Instrumen Assesmen Higher Order Thinking Skill (HOTS) pada Mata Pelajaran Matematika SMP Kelas VII Semester 1. Jurnal Riset Pendidikan Matematika, 139-151.

Gunawan. (2012). Kurikulum dan Pembelajaran. Jakarta: Rajawali Pers.

Hafisani, L. H., Annajmi, \& Arcat. (2020). Pengaruh Strategi Pembelajaran Relating, Experiencing, Applying, Cooperating, and Transferring (REACT) Terhadap Kemampuan Komunikasi Matematis Siswa Kelas VII di MTs Ash-Sohibiyah Bangun Purba. Jurnal Absis: Jurnal Pendidikan Matematika Dan Matematika, 171-179.

Hamzah. (2014). Evaluasi Pembelajaran Matematika. Jakarta: Rajawali Pers.

Ilyas, M. (2012). Keefektifan Assesmen Autentik dalam Pembelajaran Matematika. Jurnal Dinamika, 64-76.

Mardapi, D. (2012). Pengukuran, penilaian dan evaluasi pendidikan. Yogyakarta: Nuha.

Mardhiyana, D., \& Jailani, J. (2018). Pengembangan Model Asesmen Pembelajaran Matematika SMA Berdasarkan Kurikulum 2013. PYTHAGORAS: Jurnal Pendidikan Matematika, 135-148.

Mendikbud. (2016). Peraturan Menteri Pendidikan Nasional Republik Indonesia Nomor 22 tentang Standar Proses Pendidikan Dasar dan Menengah. Jakarta: Kementerian Pendidikan dan Kebudayaan Republik Indonesia. 
NCTM. (2000). Principles and standards for school mathematics. Reston, VA: The National Council of Teachers of Mathematics, Inc. .

Nurmadinah. (2017). Pengembangan Instrumen Test Hogh Order Thinking Skill (HOTS) pokok bahasan Operasi hitung Bentuk Aljabar serta Persamaan dan Pertidaksamaan Linier Satu Variabel Kelas VIII MTs Guppi Samata. Makasar: Skripsi UIN Alaudin Makasar.

Resnick, L. (1987). Education and learning to think. Washington, DC: National Academy Press. 